NASA-TM-111542

Authorized reprint from Standard Technical rubucation 1206

Copyright 1993 American Society for Testing and Materials, 1916 Race Street, Philadelphia, PA 19103

Wade C. Jackson' ${ }^{1}$ and Roderick H. Martin ${ }^{2}$

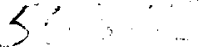

\title{
An Interlaminar Tensile Strength Specimen
}

REFERENCE: Jackson. W. C. and Martin, R. H., "An Interlaminar Tensile Strength Specimen," Composite Materials: Testing and Design (Eleventh Volume). ASTM STP 1206. E. T Camponeschi, Jr., Ed.. American Society for Testing and Materials. Philadelphia, 199.3, pp. $333-354$.

ABSTRACT: This paper describes a technique to determine interlaminar tensile strength, $\sigma_{3}$, of a fiber reinforced composite material using a curved beam. The specimen was a unidirectional curved beam, bent $90^{\circ}$, with straight arms. Attached to each arm was a hinged loading mechanism that was held by the grips of a tension testing machine. Geometry effects of the specimen. including the effects of loading arm length, inner radius, thickness, and width, were studied. The data sets fell into iwo categories: low strength corresponding to a macroscopic flaw related failure and high strength corresponding to a microscopic flaw related failure. From the data available, the specimen width and loading arm length had little effect on $\sigma_{3 \mathrm{z}}$. The inner radius was not expected to have a signiticant effect on $\sigma_{3}$. but this conclusion could not be contirmed because of differences in laminate quality for each curve geometry. The thicker specimens had the lowest value of $\sigma_{3}$ because of poor laminate quality.

KEYWORDS: composite material, carbon epoxy, interlaminar tensile strength, curved beam. delamination

Because of low interlaminar strengths of laminated composites, interlaminar failures can be a predominant failure mode. If stress singularities are present, interlaminar failure may be predicted using interlaminar fracture mechanics or average stress criteria. If stresses are finite, stress and interlaminar strength data may be applied directly. Transverse width strength, $\sigma_{2 c}$, determined from flat $90^{\circ}$ specimens is often used to represent interlaminar tensile strength, $\sigma_{3 c}$. However, if the actual interlaminar tensile strength is significantly different from the transverse width strength. predictions will be incorrect. Consequently, a method is needed to measure the interlaminar tensile strength.

Several attempts have been made to design an interlaminar tensile strength specimen. In Ref $I$. sixteen unidirectional specimens of 24 plies each were adhesively bonded together to create a 384 ply bonded laminate. A radius was machined into the specimen to give a minimum area in the center. Aluminum shanks were also bonded to the ends so that a tension load could be applied. For an XAS/914C carbon/epoxy specimen, an average $\sigma_{3 \mathrm{c}}$ of $75.0 \mathrm{MPa}$ was measured. This compared with an average $\sigma_{2 \mathrm{c}}$ of $83.0 \mathrm{MPa}$ determined from flat $90^{\circ}$ specimens. However, failure in the interlaminar tensile specimens was often close to a bond line. In Ref 2, a similar method was attempted using thick ( 50 and 100 plies) unidirectional and cross-ply laminates. A radius was machined into the specimens to give a minimum area at the center, and aluminum shanks were bonded to the ends for load application. For an AS4/3501- 6 carbon/epoxy specimen, an average $\sigma_{3}$ of $43.0 \mathrm{MPa}$ was measured. This compared to an average $\sigma_{2 \mathrm{c}}$ value of $57.6 \mathrm{MPa}$ from flat $[90]_{100}$ specimens. However, the manufacture of thick laminates and the machining were considered by the authors to be disadvantages to this type of specimen.

'U.S. Army Aerostructures Directorate, NASA Langley Research Center. Hampton, VA 23681

"Analytical Services and Materials, Inc., Hampton, VA 23666. 
In Ref 3, unidirectional curved laminates were used to determine $\sigma_{3 c}$ data for AS4/3501-6. The curved laminates were essentially L-shaped with the interlaminar tensile failure occurring around the angle. A special loading fixture had to be manufactured to apply a load normal to the loading arm to open the specimen. An average $\sigma_{3 \mathrm{c}}$ of $45.0 \mathrm{MPa}$ was measured with this type of specimen. This compared to an average $\sigma_{2 \mathrm{c}}$ value of $65.4 \mathrm{MPa}$ obtained from $[90]_{24}$ flat laminates. In Ref 4 , a semicircular curved beam specimen was used to determine $\sigma_{3 c}$ of G40-600/5245C carbon/epoxy. These laminates were of poor quality with a high void content and variations in thickness. The data from the semicircular beam were grouped into two sets: one with an average $\sigma_{3 \mathrm{c}}$ of $58.0 \mathrm{MPa}$ and the other with an average strength of $32.5 \mathrm{MPa}$. The weaker data set was considered to be a flaw related failure, whereas the stronger data set was proposed to be a true material property. Also in Ref 4 , an elliptical curved beam specimen was used to determine $\sigma_{3 \mathrm{c}}$ of T300/934 carbon/epoxy. A different manufacturing process was used that produced a very high quality part with no discernable flaws. For these specimens, a mean strength of 107.1 MPa was measured which was almost twice the in-plane transverse strength. A review of curved beam testing and interlaminar tensile failure was given in Ref 5 .

This paper describes an alternate configuration of the curved beam specimen that offers many advantages over the other methods for determining the interlaminar tension strength. A simple specimen geometry is used which is much easier to manufacture than the other specimens (i.e., no machining, bonding, or complex manufacturing processes). The specimen geometry also resembles many structural details used on aircraft such as the corners of webs and spars. In addition, the test can be performed in a simple tension testing machine without a complicated loading fixture.

\section{Specimen Configuration and Test Procedure}

The curved beam specimen is shown schematically in Fig. 1. Various widths $w$, thicknesses $t$, inner radii $r_{i}$, and loading arm lengths $L$ were used as shown in Table 1 . The material used was AS4/3501-6 carbon/epoxy. The material properties were taken from Ref 3 and were: $E_{\theta}=140$ $\mathrm{GPa} ; E_{r}=11.0 \mathrm{GPa}, G_{r \theta}=5.84 \mathrm{GPa}$, and $\nu_{r \theta}=0.0237$, where the subscript $\theta$ coincides with the fiber direction. The laminates were laid up in 300 -mm wide strips over the corner of a solid aluminum block. The corner of the block had the appropriate radius to form the inner radius indicated in Table 1. Each of the straight arms was $80 \mathrm{~mm}$ long. All the laminates were unidirectional with the fibers running in the direction shown in Fig. 1. A unidirectional layup was used to prevent matrix cracks and edge stresses from initiating delaminations [3]. The panels were cured in an autoclave according to the material manufacturer's instructions. A thermal blanket was used on the 48-ply specimens to ensure uniform heating. The specimens were then machined to the specified width from the $300-\mathrm{mm}$ panel. The exact width and thickness of each specimen were then measured with a vernier caliper. All specimens were dried prior to testing using the following cycle: $1 \mathrm{~h}$ at $95^{\circ} \mathrm{C}, 1 \mathrm{~h}$ at $110^{\circ} \mathrm{C}, 16 \mathrm{~h}$ at $125^{\circ} \mathrm{C}$, and $1 \mathrm{~h}$ at $150^{\circ} \mathrm{C}$.

Loads were applied via a hinged steel loading fixture which is shown in Figs. 1 and 2 . This fixture allowed the specimen to be tested in a standard tension testing machine. Initially, aluminum hinges that were bonded or clamped to the loading arms were used for loading. However, the adhesive bond invariably failed prior to interlaminar tensile failure, or high failure loads would often bend or even break the aluminum hinges. The method of load application is also included in Table 1. A screw-driven machine was used with the displacement controlled at $0.5 \mathrm{~mm} / \mathrm{min}$. Loads and displacements were digitally recorded and the initial interlaminar tension failure was generally recorded as a sudden decrease in load. To ease the observation of the location of interlaminar tensile failure the sides of the specimen were painted white with a water-based typewriter correction fluid. 


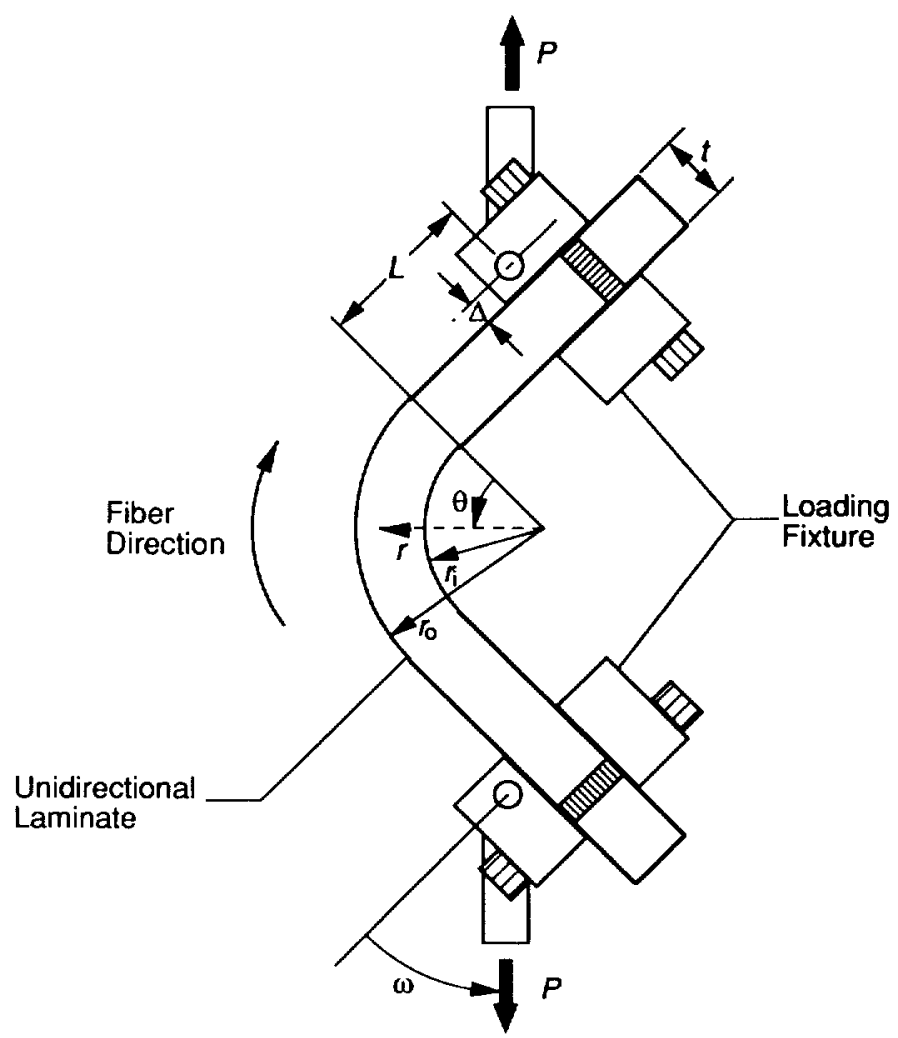

FIG. 1-Schemanic of interlaminar tensile strength specimen.

TABLE 1 - Test matrix.

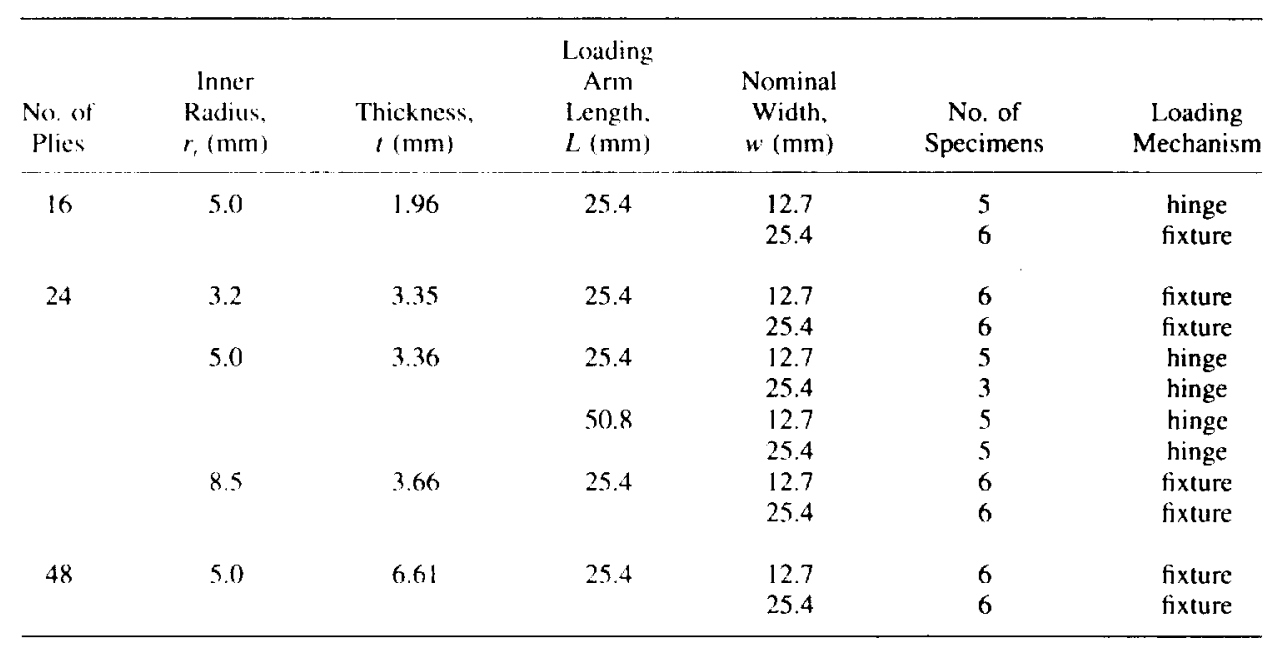




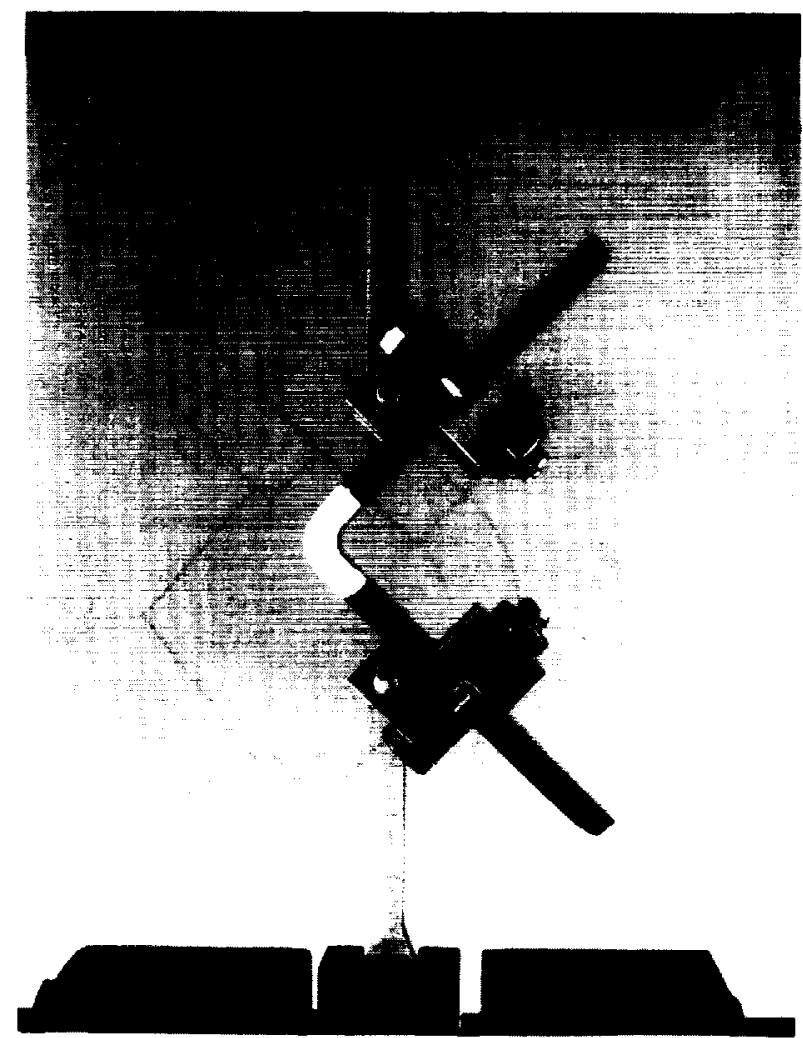

FIG. 2-Photograph of interlaminar tensile strength specimen and test fixture.

\section{Analysis}

To determine the stresses throughout the cross-section, Lekhnitskii solutions for a curved beam with an end load and for a curved beam with a moment were used $[6]$. Corrections were made to the Lekhnitskii solution to produce a solution for a pure end load. Corrections were also made to the applied moment to account for reductions in moment arm length. An elementary bearn theory solution and a NASTRAN finite element analysis were also used to compare with the Lekhnitskii solution.

\section{Lekhnitskii Solution}

Lekhnitskii developed two sets of equations for the stresses in a curved beam segment with cylindrical anisotropy [6]. A set of equations was developed for a curved beam with an end load and for a curved beam with a moment at each end. The stresses caused by the loading shown in Fig. 1 were calculated by superimposing the stresses from Lekhnitskii's two solutions (Fig. 3). However, the stress distribution in the curved segment in Lekhnitskii's end load solution was actually produced by an end moment resultant as well as an end force resultant. Consequently, corrections were made to the end load solution by using Lekhnitskii's moment solution to subtract out the stresses caused by this additional moment (Fig. 3). Reference 6 did not indicate that the stress field for the end load solution included the effect of an end moment resultant. Appendix A contains the stress equations for the two Lekhnitskii solutions and the modifications to the end load solution.

Since Lekhnitskii's solutions were for a curved beam segment only, the force applied to the loading arm was translated to the end of the curved segment as a moment and a force (Fig. 3). The stress equations are very sensitive to small changes in the moment arm length. Consequently, 


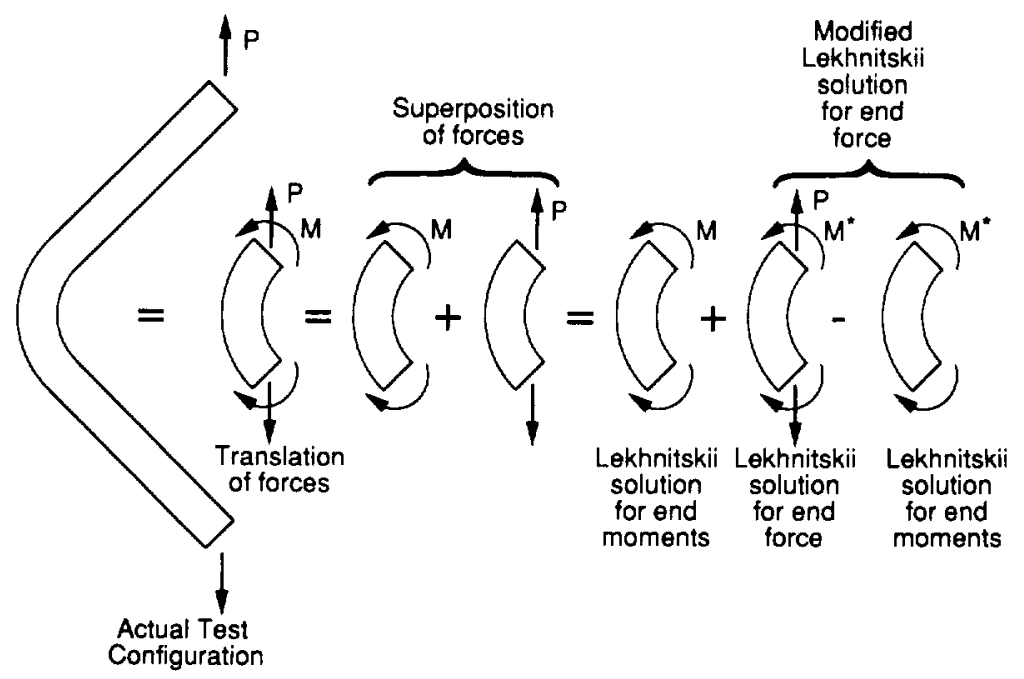

FIG. 3-Superposition of Lekhnitskii solutions to obtain stresses for test configuration.

corrections were developed to obtain a more accurate moment arm length (Appendix B). Corrections were calculated to include the offset of the loading pin from the neutral axis $(\Delta+t / 2$; see Fig. 1) and the shortening of the moment arm caused by the rotation and displacement of the end of the beam prior to failure. The correction due to the loading pin offset was determined to be the only significant effect relative to the experimental error and was the only corrertion included in the final moment calculation. This correction reduced the moment arm length by up to $30 \%$ in some configurations. Corrections caused by the rotation and displacement of the end of the beam were a maximum $4.1 \%$. This correction was greatest in the thin specimens.

The radial stress, including corrections, at any location is given by Eq 1. The derivation is contained in Appendices $\mathrm{A}$ and $\mathrm{B}$.

$$
\begin{aligned}
\sigma_{r}=\frac{P}{r \cdot g_{1}}\left[\left(\frac{r}{r_{n}}\right)^{\beta}+\right. & \left.\rho^{\beta}\left(\frac{r_{c}}{r}\right)^{\beta}-1-\rho^{\beta}\right] \sin (\theta+\omega) \\
& -\frac{P\left(L \cos (\omega)-\frac{1}{2}\left(r_{i}+r_{0}\right) \sin (\omega)-\left(\Delta+\frac{t}{2}\right) \sin (\omega)\right)}{r_{0}^{2} \omega g} \\
& {\left[1-\frac{1-\rho^{\kappa+1}}{1-\rho^{2 \kappa}}\left(\frac{r}{r_{n}}\right)^{\kappa} 1-\frac{1-\rho^{\kappa}}{1-\rho^{2 \kappa}} \rho^{\kappa+1}\left(\frac{r_{o}}{r}\right)^{\kappa+1}\right] }
\end{aligned}
$$

The analysis assumed a state of plane strain. However, the stresses calculated by assuming a state of plane stress or plane strain were almost identical. The variables in Eq 1 are defined in the appendices. The geometry variables are also shown in Fig. 1. The expressions for the tangential stresses and shear stresses are given in Appendix B. For the loading arrangement shown in Fig. 1, $\omega$ is equal to $45^{\circ}$, and $\mathrm{Eq} 1$ reaches a maximum for any value of radius, $r$, at $\theta=45^{\circ}$. To determine the location, $r$, where $\sigma$, is a maximum. Eq 1 may be differentiated with respect to $r$ and equated to zero or may be determined by incrementally increasing $r$. The latter technique was employed in this study. 


\section{Elementary Beam Theory}

An elementary beam theory method to determine the maximum radial stress was proposed in Ref 5 as

$$
\left(\sigma_{r}\right)_{\max }=\frac{3 P\left(L \cos (\omega)-\left(\Delta+\frac{t}{2}\right) \sin (\omega)\right)}{2 \omega t\left(r_{i} r_{0}\right)^{1 / 2}}
$$

The variables are defined the same as those used in Eq 1. This expression accounts for the maximum stress location being at a position other than the center thickness and may be used as an approximation of the maximum radial stress.

\section{Finite Element Analysis}

A MSC/NASTRAN finite element analysis was conducted on the specimen to determine the stress distribution. By using symmetry, only half of the specimen was modeled (one loading arm and half of the curved region). The force was applied to the straight loading arm so that a comparison could be made with the Lekhnitskii solution to determine if the translation of the loading force to the end of the curved segment affected the stresses in the region of interest $(\theta=$ $45^{\circ}$ ). Four-noded quadrilateral elements were used with 24 elements in the thickness direction and one element for every degree in the circumferential direction. A transition was made to a coarser mesh to model the straight loading arm. For convenience, the force was applied at the neutral axis so a loading pin height correction was not necessary. The effects of geometric nonlinearities and large displacements were not modeled.

\section{Analytical Results}

The radial and tangential stress distributions, $\sigma_{r}$ and $\sigma_{\theta}$, in the thickness direction are shown for a 3.0 -mm-thick curved laminate with an inner radius of $5.0 \mathrm{~mm}$ at $\theta=45^{\circ}$ and a moment arm length. $L$, of $25 \mathrm{~mm}$ in Fig. 4. The shear stresses are zero at $\theta=45^{\circ}$ and are an order of magnitude smaller than the radial stress for other values of $\theta$. Hence, the shear stresses may be considered negligible. The radial stress increases from zero at the free surface and reaches a maximum prior to the center of the specimen. The tangential stress was a maximum at the free surfaces and varied from tension to compression as $r$ was increased. In the region where the radial stress is a maximum, the tangential stress is of the same magnitude. Since the strength in the circumferential direction (fiber direction) is typically two orders of magnitude higher than in the radial direction, a failure at this location was attributed to radial stress alone.

For comparison, the stress results from the finite element analysis and from the modified Lekhnitskii solution are both shown in Fig. 4. The maximum stress predicted by beam theory (Eq 2) is also shown. There were no differences between the stress predictions from the finite element analysis and the Lekhnitskii solution. Consequently, the translation of forces in the Lekhnitskii solution was assumed not to have affected the stresses in the region of interest $\left(\theta=45^{\circ}\right)$. An analysis of a similar configuration indicated that the stresses were affected by the loading method only within a region that was within $15^{\circ}$ of the ends of the curved segment [3]. The beam theory prediction was approximately $8 \%$ lower than the maximum stress predicted by the other two methods and, hence, would give conservative values of $\sigma_{3 \mathrm{c}}$

The distribution of radial stress, $\sigma_{r}$, and tangential stress, $\sigma_{m}$, through the thickness for beams of three different thicknesses is plotted at $\theta=45^{\circ}$ in Fig. 5. All the beams had an inner radius of 5.0 $\mathrm{mm}$ and a loading arm length of $25 \mathrm{~mm}$. The loads were applied at the neutral axis of the loading 


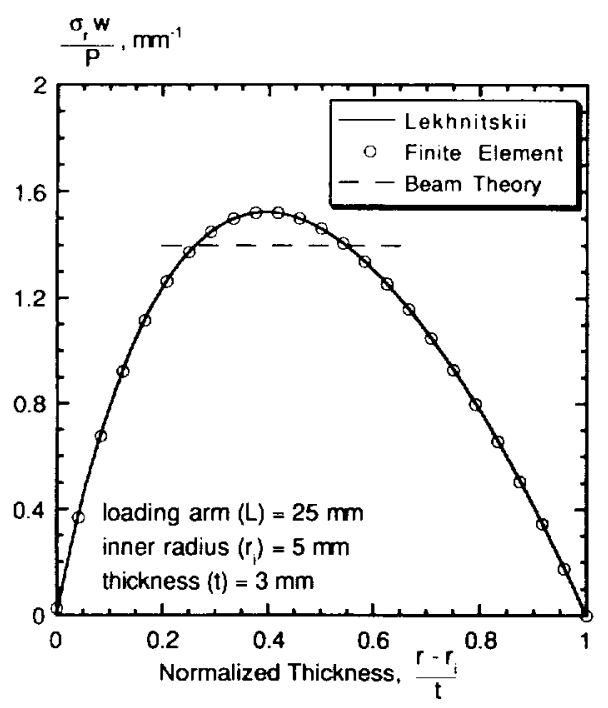

$$
\frac{\sigma_{\theta} w}{P} \cdot m m^{-1}
$$

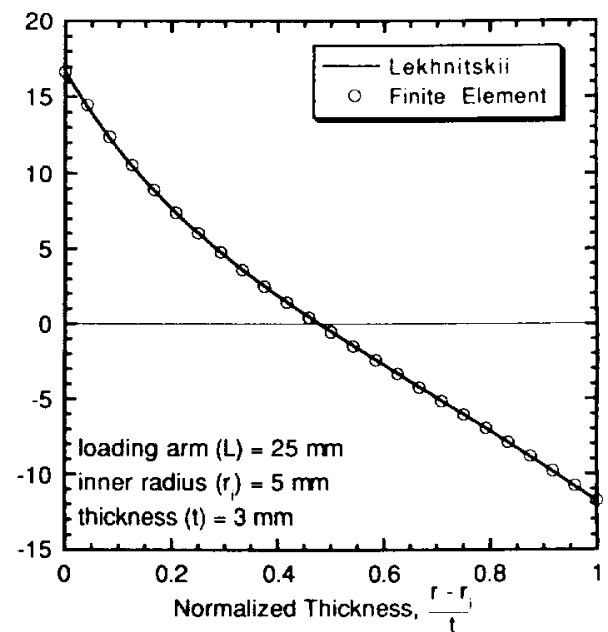

FIG. 4-Comparison of analvtical data reduction techniques.

arm, and small corrections to the moment arm were not included. For a given force, the thicker beams had a lower value of maximum radial stress than the thinner beams. Also, the location of the maximum radial stress moved away from the center and closer to the inner radius as thickness was increased. The maximum tangential stress was lower for thicker beams, and the location where $\sigma_{H}$ $=0$ did not change significantly with thickness. Also, for the thicker 48 -ply specimens, the curve is flatter near the region of maximum radial stress than for the thinner specimens. Consequently, a larger percentage of the cross-sectional area is under high stress for the thicker specimens.
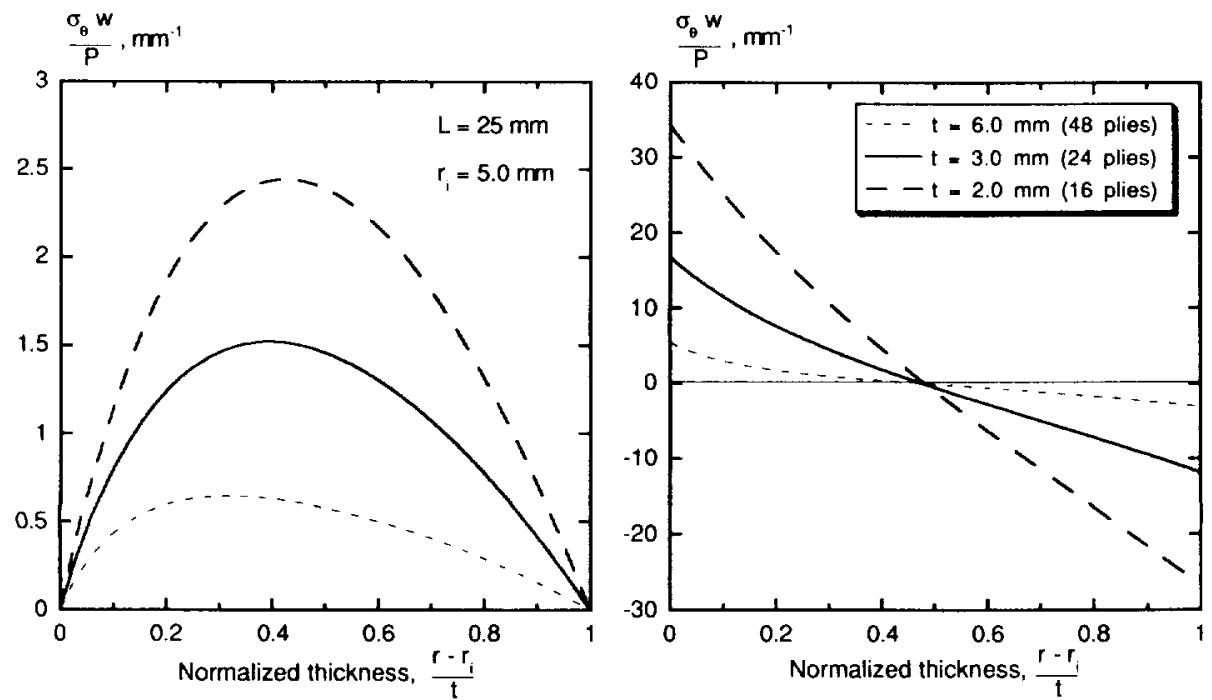

FIG. 5-Effect of specimen thickness on stress distribution. 


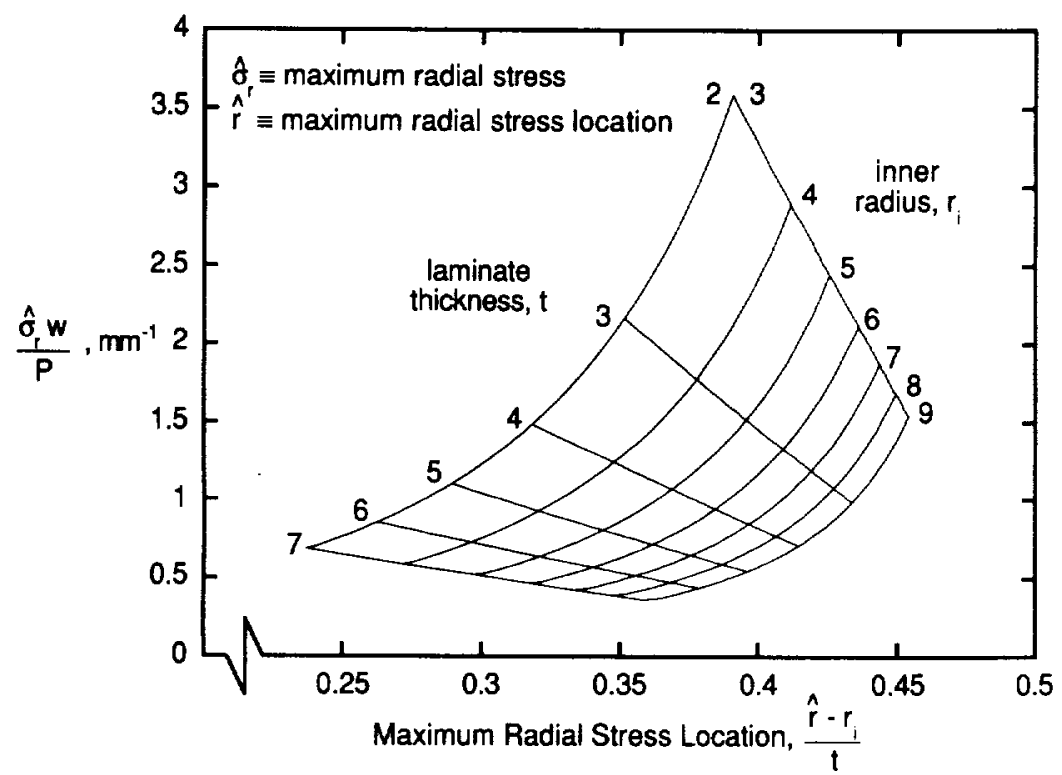

FIG. 6-Location of maximum radial stress with different thicknesses and inner radii.

The location of the maximum radial stress with various thicknesses and inner radii is given as a carpet plot in Fig. 6. Again, the loads were considered to be applied at the neutral axis of the loading arm, and small corrections to the moment arm were not included. As the inner radius increased, the maximum radial stress decreased, and the location of maximum radial stress moved towards the center of the thickness. Additionally, as the laminate thickness increased, the maximum radial stress decreased, and the location moved away from the center of the thickness towards the inner radius.

\section{Experimental Results}

\section{Load-Displacement Curves}

Typical load-displacement curves are shown for several specimen geometries in Fig. 7. In these curves, both the loading arm and specimen width are equal to $25.4 \mathrm{~mm}$. The load-displacement relationships are affected by the compliance of the machine and loading fixture. Machine and fixture compliances were most evident in the stiff 48 -ply specimens because of small specimen displacements at high loads.

In many of the specimens, subcritical damage developed before failure occurred where the specimen had a significant loss of load and stiffness. The strength was calculated based on the load corresponding to this initial damage if subcritical damáge developed prior to failure. The development of subcritical damage caused small load drops which resulted in steps in the loading curves. The wider specimens had these steps more often than the narrower specimens. An example of a stepped loading curve is shown in Fig. 7 for the 24 -ply specimen with the 3.2-mm radius. The cause for these steps is discussed below. The 16-ply specimens did not have any steps before a sudden failure occurred which resulted in an approximately $80 \%$ drop in load. For the 24-ply specimens with a radius of $3.2 \mathrm{~mm}$, half of the $25.4-\mathrm{mm}$-wide specimens had steps while none of the 12.7 mm-wide specimens had steps. For the 24 -ply 8.5 -mm radius specimens, only one of the $25.4-\mathrm{mm}$ - 


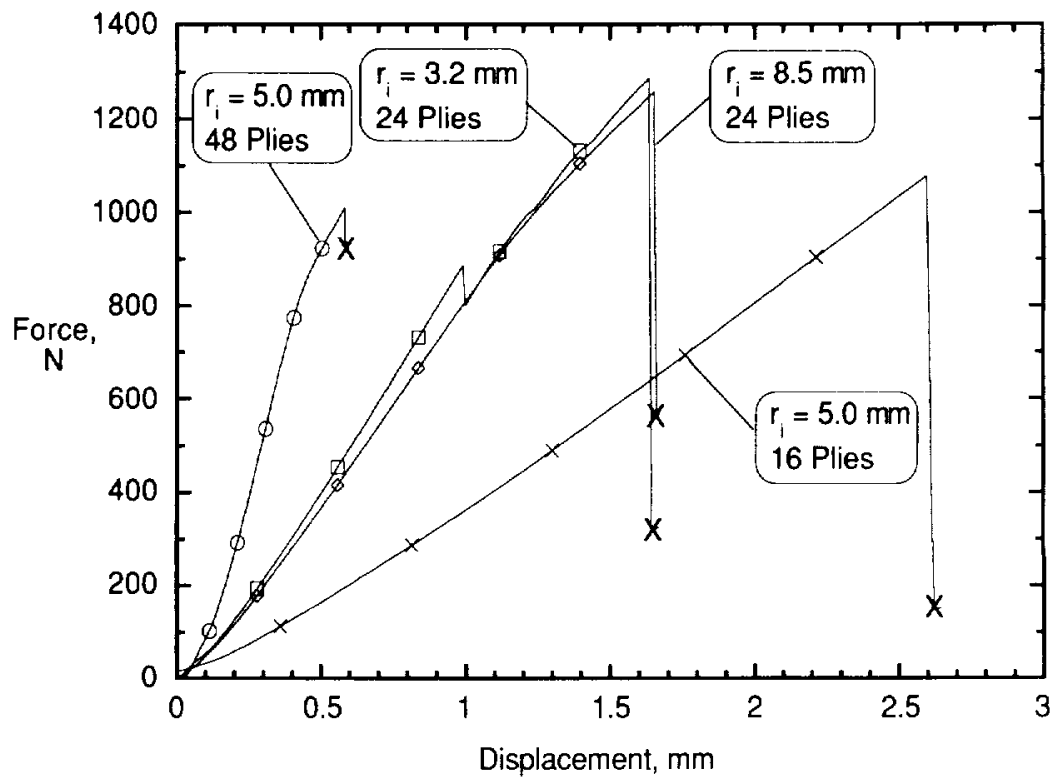

FIG. 7-Typical load-displacement curves.

wide specimens had steps in the loading curve, and none of the 12.7-mm-wide specimens had load drops. When the 24-ply specimens failed, the load dropped approximately $50 \%$ from the maximum. In general, the load dropped a greater percentage for specimens that failed at higher loads. The 48 ply specimens were unloaded at the first sign of damage as indicated by a small load drop (approximately $70 \mathrm{~N}$ ) and circumferential crack. These damaged specimens were later reloaded until a large drop in load occurred. Most of the load curves had several more steps before a final failure occurred. The final failure occurred at load that was more than twice the value at which initial damage developed. At failure, the load would typically drop by $40 \%$.

After failure, circumferential cracks in the curved segment were observed on the edges of all specimens. These cracks extended slightly into the loading arm. Figure 8 shows an example of a circumferential crack for a 24-ply specimen with an inner radius of $8.5 \mathrm{~mm}$. The 16-ply specimens tended to have the most cracks with approximately seven cracks per side. Most specimens, however, had one to three cracks on each side. These cracks were rarely in the same radial location on opposite sides of the same specimen. The small load steps that occurred prior to failure resulted in a small circumferential crack on one or both edges. For the 48-ply specimens, the cracks formed by the load steps always formed near mid-thickness.

\section{Failure Strengths}

The interlaminar strength, $\sigma_{3 k}$, was calculated for each specimen using the modified Lekhnitskii solution (Eq 1) and the load at which initial damage was detected. The strengths along with the mean and coefficient of variation are given in Table 2. Figure 9 shows the individual strength measurement for each of the test specimens. The strengths were expected to be approximately equal for each data set. However, the data sets generally fell into a high or a low category of strength. The eight sets of data that fell into the low strength category were composed of all the 48-ply specimens and the 24-ply specimens with inner radii of $8.5 \mathrm{~mm}$ and $5.0 \mathrm{~mm}$. The high strength set consisted of 


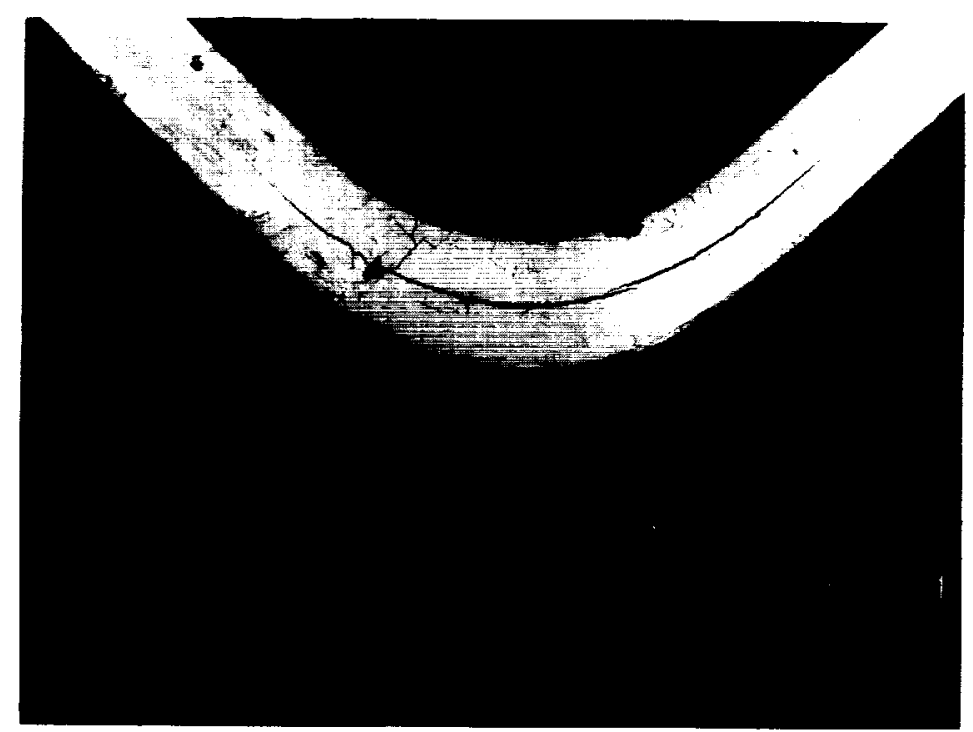

FIG. 8-Circumferential cracks on the edge of a 24-ply specimen with an $r_{i}=8.5 \mathrm{~mm}$.

TABLE: 2---Interlaminar tensile strengths.

\begin{tabular}{|c|c|c|c|c|c|c|}
\hline $\begin{array}{l}\text { No. of } \\
\text { Plies }\end{array}$ & $\begin{array}{c}\text { Inner } \\
\text { Radius. } \\
r_{i} \text { (mmI) }\end{array}$ & $\begin{array}{l}\text { Loidding } \\
\text { Arm } \\
\text { Length, } \\
\text { L. }(\mathrm{mm})\end{array}$ & $\begin{array}{l}\text { Nominal } \\
\text { Width. } \\
W(\mathbf{m m})\end{array}$ & $\begin{array}{l}\text { Interlaminar Strength. } \sigma_{i}, \\
(\mathrm{MPa})\end{array}$ & Mean & CV, \% \\
\hline \multirow[t]{2}{*}{16} & 5.0 & 25.4 & 12.7 & $\begin{array}{c}92.9 .85 .5 .66 .7 \\
73.7 .88 .2\end{array}$ & 81.4 & 13.3 \\
\hline & & & 25.4 & $\begin{array}{l}72.6,77.6,84.9 \\
88.1,100.4,62.7\end{array}$ & 81.1 & 16.2 \\
\hline \multirow[t]{8}{*}{24} & 3.2 & 25.4 & 12.7 & $\begin{array}{l}89.4,75.4,88.1 \\
65.7,66.0,68.8\end{array}$ & 75.5 & 14.3 \\
\hline & & & 25.4 & $\begin{array}{l}18.0,56.2,76.4 \\
39.7,40.8,53.4\end{array}$ & 47.4 & 41.4 \\
\hline & 5.0 & 25.4 & 12.7 & $25.6,21.6,32.3,33.8,36.6$ & 30.0 & 20.7 \\
\hline & & & 25.4 & $36.7,37.7,32.8$ & 35.7 & 7.3 \\
\hline & & 50.8 & 12.7 & $37.4,41,2,34.0,50.2,22.3$ & 37.0 & 27.5 \\
\hline & & & 25.4 & $47.6,34.2,47.0,35.7,39.5$ & 40.8 & 15.3 \\
\hline & 8.5 & 25.4 & 12.7 & $\begin{array}{l}48.7,43.8,49.9 \\
28.8,44.6,22.2\end{array}$ & 39.7 & 28.8 \\
\hline & & & 25.4 & $\begin{array}{l}15.9,14.7,29.9 \\
34.2,47.8,32.9\end{array}$ & 29.2 & 42.6 \\
\hline \multirow[t]{2}{*}{48} & 5.0 & 25.4 & 12.7 & $\begin{array}{l}15.8,16.8,16.1 \\
16.4,16.7,18.5\end{array}$ & 16.7 & 5.5 \\
\hline & & & 25.4 & $\begin{array}{l}17.3,15.6,16.8 \\
16.9,18.2,17.7\end{array}$ & 17.1 & 5.3 \\
\hline
\end{tabular}




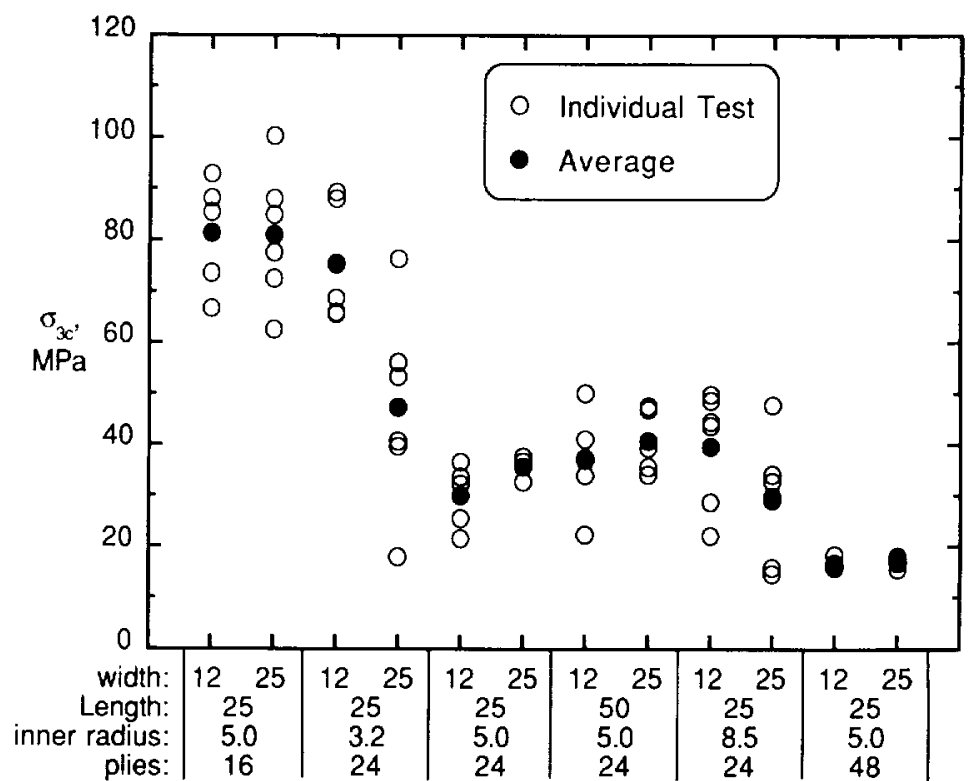

FIG. 9-Experimental interlaminar tensile strengths

the 16-ply specimens and the $12.7-\mathrm{mm}$ wide 24 -ply specimens with the $3.2 \mathrm{~mm}$ radius. The $24-$ ply 25.4-mm-wide specimens with the $3.2-\mathrm{mm}$ radius had the most scatter with strengths that fell into both categories. However, a significant amount of scatter occurred within each data set. For each curve configuration, the effect of different width specimens was small. In the specimens where the loading arm length was doubled, the strength increased slightly. This apparent strength increase may be caused by the general scatter of the data.

Since small sample sizes were used to measure the interlaminar strength, an estimation of experimental uncertainty was performed |7|. Many of the variables, such as the modulus in the radial direction, are not known with a high degree of accuracy. Consequently, it was desirable to know which measurements were most crucial to the accuracy of the interlaminar strength prediction. The estimation method consisted of first estimating the uncertainty of each variable and then applying a relationship that specifies how the uncertainty of individual variables propagates into the overall uncertainty in the prediction [7]. The overall uncertainty, $U$, was calculated as

$$
U=\left[\sum_{i=1}^{n} \delta_{i}^{2}\right]^{1 / 2}
$$

where $i$ is the variable number, $n$ is the number of variables, and $\delta_{i}$ is the change in the overall prediction due to the uncertainty in variable $i$. The modified Lekhnitskii solution was used for the analysis. The uncertainties in the test results are shown in Table 3 for three different thicknesses, $t$, for the case of an inner radius, $r$, of $5.0 \mathrm{~mm}$, a loading arm length, $L$, of $25.4 \mathrm{~mm}$, and a width, $w$, of $25.4 \mathrm{~mm}$. The percent uncertainty ranged from $6.9 \%$ in the 48 -ply specimens to $14.0 \%$ in the 16 ply specimens. The two variables that contributed the most to the overall uncertainty were the thickness and the loading arm length. The analysis was also fairly sensitive to the value of the inner radius. However, the uncertainty in the material properties did not affect the overall accuracy of the prediction. A large estimated uncertainty of $30 \%$ in the radial modulus, $E$, resulted in less than a $1.3 \%$ uncertainty in the predicted value of radial stress. 
TABLE 3-Estimation of experimental uncerlainties $\left(r_{1}=5.0 \mathrm{~mm}, L=25.4 \mathrm{~mm}\right.$ and $\left.n=25.4 \mathrm{~mm}\right)$.

\begin{tabular}{|c|c|c|c|c|c|}
\hline \multirow[b]{2}{*}{ No. (i) } & \multirow[b]{2}{*}{ Variable } & \multirow[b]{2}{*}{ Uncertainty } & \multicolumn{3}{|c|}{ Error for individual variables, $\%$} \\
\hline & & & 16-ply & 24-ply & $48-p l y$ \\
\hline 1 & $E_{r}$ & $\pm 30 \%$ & 0.0 & 0.6 & 1.3 \\
\hline 2 & $E_{H}$ & $\pm 10 \%$ & 0.1 & 0.2 & 0.5 \\
\hline 3 & $G_{r i \prime}$ & $\pm 20 \%$ & 0.1 & 0.2 & 0.5 \\
\hline 4 & $\nu_{r \prime \prime}$ & $\pm 20 \%$ & 0.0 & 0.0 & 0.0 \\
\hline 5 & $L$ & $\pm 1 .(10 \mathrm{~mm}$ & 3.8 & 4.2 & 4.7 \\
\hline 6 & $P$ & $\pm 1 \%($ load cell $)$ & $1 . \dot{0}$ & 1.0 & 1.0 \\
\hline 7 & $r_{1}$ & $\pm 0.20 \mathrm{~mm}$ & 3.1 & 2.8 & 2.3 \\
\hline 8 & $t$ & $\pm 0.20 \mathrm{~mm}$ & 1.3 .1 & 7.6 & 4.1 \\
\hline \multirow[t]{4}{*}{9} & $w$ & $\pm 0.05 \mathrm{~mm}$ & 0.2 & 0.2 & 0.2 \\
\hline & & Maximum $\sigma_{r}, \mathrm{MPa}$ & 87.2 & 3.5 .1 & 17.1 \\
\hline & & Overall uncertainty $(U)$ & \pm 12.2 & \pm 3.2 & +1.2 \\
\hline & & (Percent uncertainly) & $(14.0 \%)$ & $(9.2 \%)$ & $(6.9 \%)$ \\
\hline
\end{tabular}

\section{Fracture Patterns}

Several specimens of each configuration were cut perpendicular to the fiber direction at $\theta=45^{\circ}$ using a low-speed diamond saw. The cut surfaces were then examined under a microscope to observe the fracture pattern across the width of the specimen. The observations from the cut surfaces are listed below. In addition, the fiber volume fraction was observed to vary through the thickness. This variation was quantified by measuring the ply thickness variation across the thickness using a microscope. The average ply thickness in a small region was determined by dividing a known distance $(0.824 \mathrm{~mm})$ by the number of plies contained in that distance. The results of these measurements are shown in Fig. 10. In general, the quality of the laminates was highest in

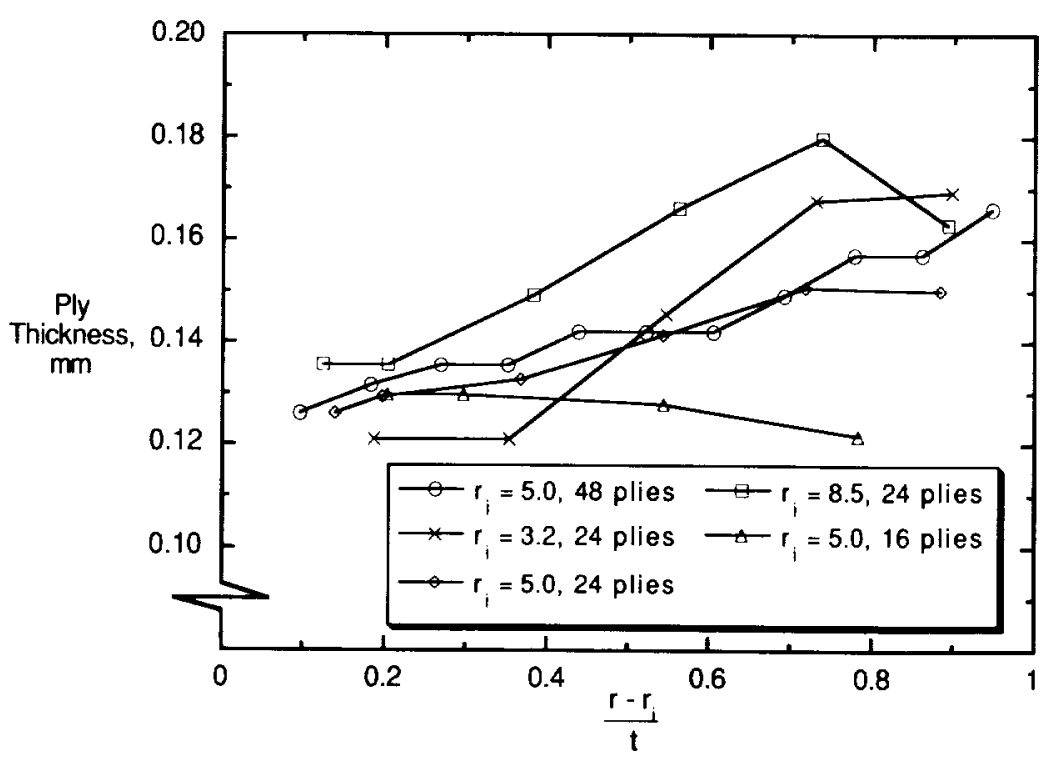

FIG. 10-Variation of ply thickness through the thickness. 
the inner half of the thickness which corresponded to the region with the smallest ply thicknesses. In most laminates, the ply thicknesses increased steadily from the inner radius to the outer radius.

The 16-ply specimens with an inner radius of $5.0 \mathrm{~mm}$ had the highest average value of interlaminar strength (Fig. 9). These laminates also appeared to be of the best quality. The crosssections were not observed to contain large resin pockets or voids like many of the other configurations. Also, the ply thickness did not change significantly across the thickness of the specimen (Fig. 10). The resin-rich regions between the plies were observed to be very small. The average ply thickness at $\theta=45^{\circ}$ was $0.123 \mathrm{~mm}$ which was the lowest of all the specimen configurations. The fracture pattern consisted of numerous cracks scattered across the entire cross-section (Fig. 11). Most cracks were translaminar and discontinuous with many branches which gave the fracture pattern a "shattered" appearance. The cracking appeared to be more extensive in the higher strength specimens than in the lower strength specimens. There was no signilicant difference between the failure patterns in the different width specimens.

The 24-ply specimens with an inner radius of $3.2 \mathrm{~mm}$ also had a high average strength (Fig. 9). These laminates had more than a $40 \%$ increase in ply thickness from the inner to the outer radius. Consequently, there were large resin-rich layers between the plies toward the outer radius. However, no large voids were observed. The failure pattern for the $25.4-\mathrm{mm}$-wide specimens consisted of several long cracks on the outer half of the thickness which tended to be predominantly interlaminar. On the inner half, the cracks were more translaminar with many branches that were similar to the cracks in the 16-ply specimens but not nearly as dense. No specific region existed where the cracks were more concentrated. A lower and a higher strength $12.7-$ mm-wide specimen were examined and found 10 contain fewer cracks than the $25.4-\mathrm{mm}$-wide specimens. The higher strength specimen contained two interlaminar cracks (interfaces of plies $7 / 8$ and $11 / 12$ from inner radius) that were connected by a translaminar crack to create a crack that spanned the entire width (Fig. 12). The lower strength specimen contained a single crack (interface of $12 / 13$ from inner radius) near the edge which was connected to two cracks that ran two thirds of the way across the width of the specimen.

The set of 24-ply specimens that had an inner radius of $5.0 \mathrm{~mm}$ had an interlaminar strength that fell in the lower group (Fig. 9). These specimens were also used to determine the effects of a change in moment arm length on the interlaminar strength. The ply thicknesses increased approximately $20 \%$ from the inner radius to the outer radius (Fig. 10). On the outer half of the thickness, a large resin-rich layer was observed between every group of four plies. These large resin-rich layers may have developed during the manufacturing process where the laminate was debulked every four plies. The failure in all of the specimens occurred primarily on a single interface in the resin-rich layer between plies 8 and 9 from the outer surface (Fig. 13). The low strengths may have resulted because of the failure at this manufacturing defect. No difference in the failure pattern was observed for the different moment arm lengths or specimen widths.

The 24-ply specimens with an inner radius of $8.5 \mathrm{~mm}$ had low strength values (Fig. 9). These specimens also had the highest average ply thickness $(0.152 \mathrm{~mm})$ in the curved region of any of the

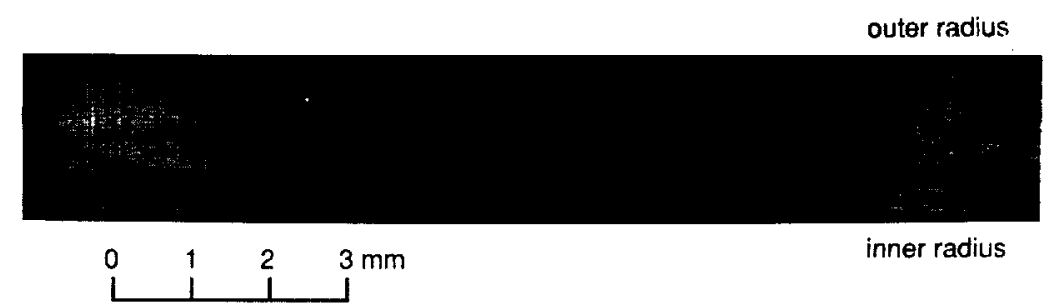

FIG. 11-Cross-section of interlaminar tensile failure of a l6-ply specimen. 

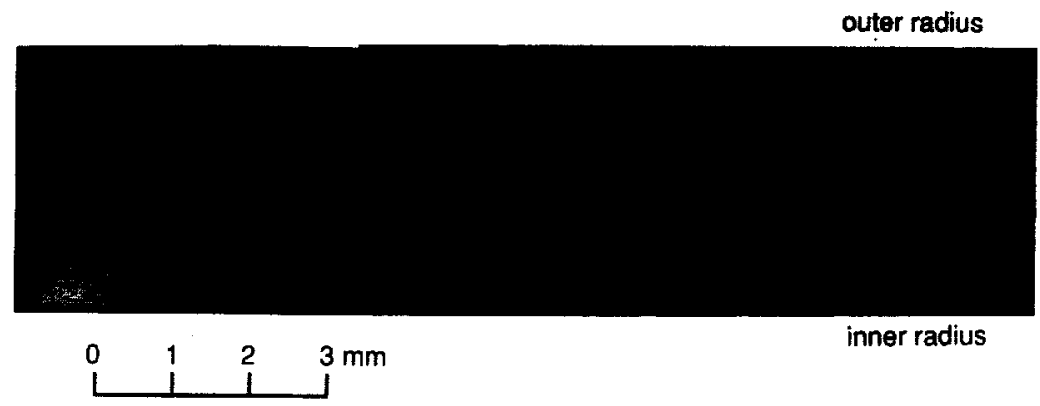

inner radius

FIG. 12-Cross-section of interlaminar tensile failure of a 24-ply specimen with an $r_{1}=3.2$ $m m$.

configurations. The laminate thickness around the radius increased by as much as $25 \%$ going from the edge to the center of the arc which resulted in a significantly higher resin content than the other 24-ply specimens. In addition, many small voids and resin pockets were observed across the cut section. The fiber volume fraction also varied across the thickness with the thickest plies and largest resin-rich regions in an area two thirds of the way from the inner radius. Many interlaminar and translaminar cracks were observed throughout the two 25.4-mm-wide specimens that were examined. The stronger of these two specimens had more extensive cracking, and the largest cracks were located approximately $45 \%$ of the way through the thickness. The weaker specimen had more voids and resin-rich regions and did not have a predominant cracking path across the width. In addition to these cracks, both specimens had large translaminar cracks that ran through the resin-rich region in the outer half of the thickness. The strongest of the 12.7-mm-wide specimens was also sectioned and examined. This specimen failed primarily on a single interface between plies 6 and 7 from the inner radius and had no cracking in the upper half of the specimen.

The 48-ply specimens had the lowest values of interlaminar strength and the least strength variability (Fig. 9). The area closest to the outer radius was observed to contain several large voids as well as large resin pockets. The ply thickness increased 18\% from the inner radius to the outer radius (Fig. 10). The resin-rich regions between the plies were much larger near the outer radius than near the inner radius. The individual plies could be easily distinguished across the entire section without polishing the surface. During loading, as previously mentioned, all of these specimens had many small subcritical failures which were detected audibly and by a small drop in the
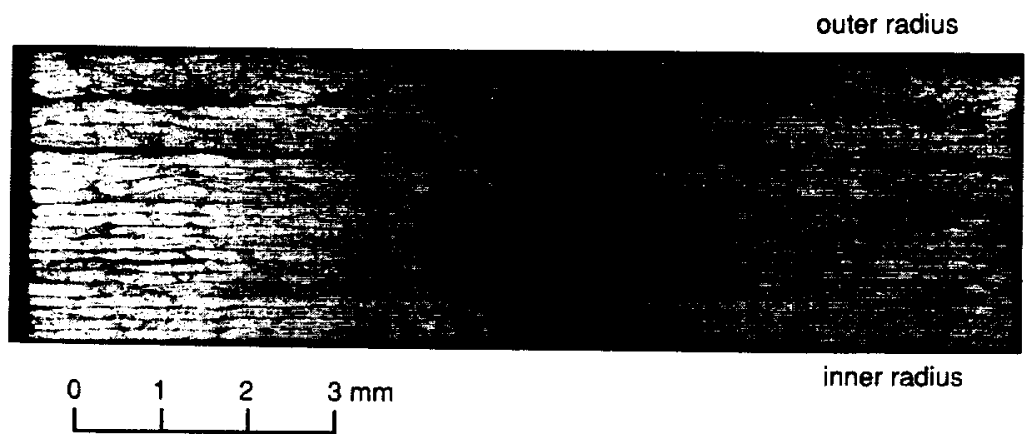

FIG. 13-Cross-section of interlaminar tensile failure of a 24-ply specimen with an $r_{i}=5.0$ $m m$ 

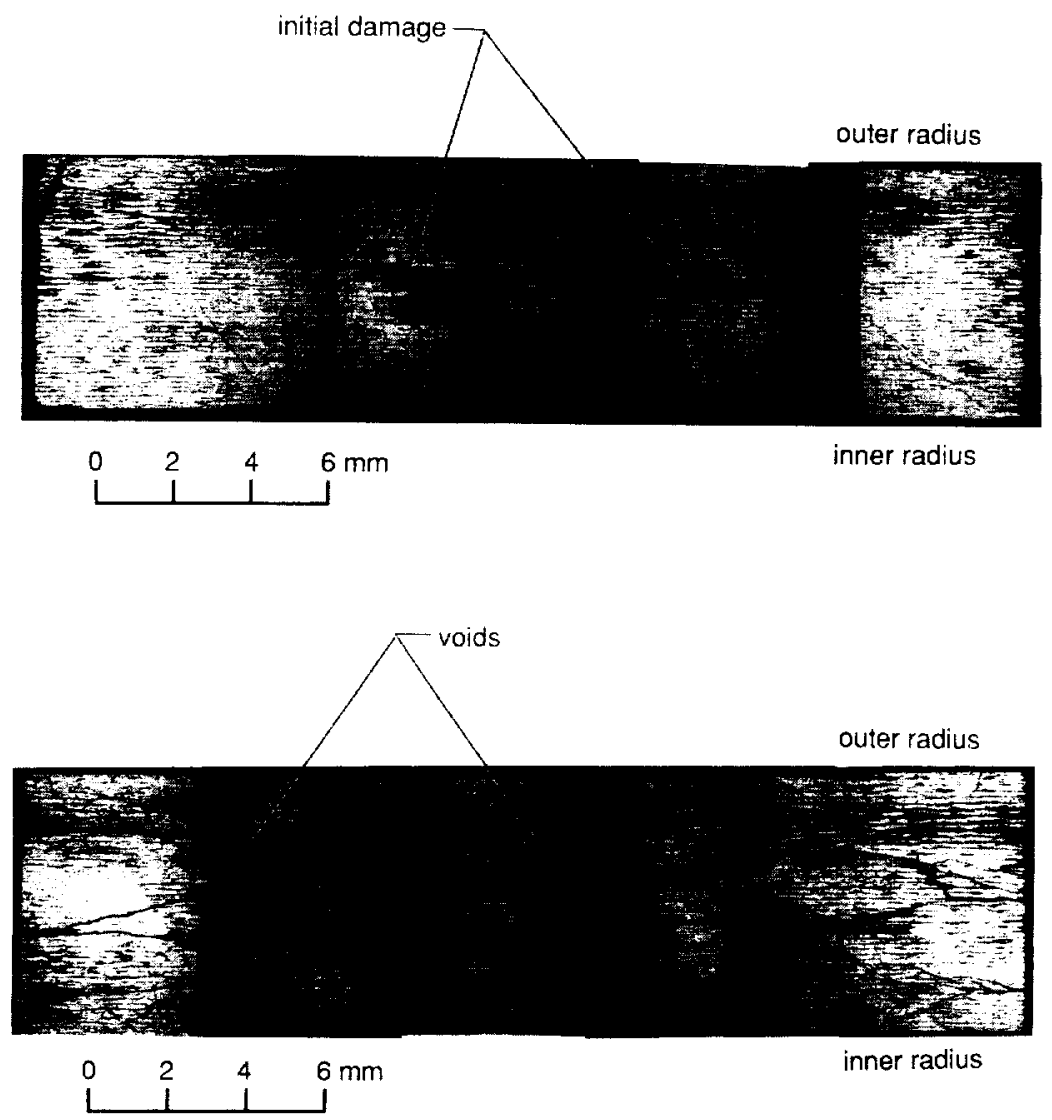

FIG. 14-Cross-sections of interlaminar tensile failure of 48-ply specimens.

load. Two specimens (12.7- and 25.4-mm-wide) were sectioned after the first subcritical failure was detected. In both specimens, three small cracks were observed between the ply interfaces in the mid-section, and it was these cracks that caused the small load drop. The photomicrograph of the 25.4-mm-wide section is shown in Fig. 14a. This interlaminar cracking occurred primarily at the interface between plies 26 and 27 (from the inner radius) in the 12.7 -mm-wide specimen and between plies 28 and 29 in the $25.4-\mathrm{mm}$ specimen. On further loading, the cracks would accumulate and finally coalesce as shown by a section of a different specimen loaded to failure (Fig. 14b). When the cracks coalesce, a more significant load drop occurred. Two specimens of each width were sectioned following final failure. The greatest concentration of cracks was located in the inner half of the radius. This region contained numerous branching translaminar cracks. The cracks in the outer half of the radius were primarily interlaminar. Several cracks were also observed emanating from large voids (Fig. 14b).

\section{Discussion}

Unlike the transverse tension specimen discussed in Ref 8 , the interlaminar tension specimen is not stressed uniformly. The maximum radial stress occurs at a single point through the thickness and around the curved portion. However. the maximum stress does have a constant value at any 
point across the width. Therefore, any reduction of width should reduce the probability of large flaws in that section and give higher strengths. However, the mean $\sigma_{3 \mathrm{c}}$ values of the wider specimens were very similar to the narrower specimens indicating little or no effect of width on $\sigma_{3 \mathrm{c}}$. Also, the strength measurements were not affected significantly by the two loading arm lengths, $L$, used in this study.

Since the effects of width and loading arm length were considered insignificant relative to the scatter, a mean $\sigma_{3 c}$ was calculated for all specimens with the same curve geometry and plotted as bars in Fig. 15. The two data sets for the 24-ply specimens with an inner radius of $3.2 \mathrm{~mm}$ were not combined since several of the $25.4-\mathrm{mm}$-wide specimens had different failure modes because of the development of subcritical damage prior to failure. The range of scatter is also shown for all the data sets. A large range of interlaminar strengths was obtained for the five curve geometries. The differences in the mean values of interlaminar strength are indicative of laminate quality rather than geometry effects. For thicker laminates, a larger volume is under high stress, and the probability of large flaws being present is increased. Therefore, if all the laminates were of equal quality with an equal distribution of flaws, the thicker laminates should have lower values of $\sigma_{3 \mathrm{c}}$. However, the effect of thickness cannot be readily compared in the experimental results since laminate quality was inversely proportional to thickness. Consequently, the trend of decreasing strengths with increasing thicknesses must be attributed to laminate quality which resulted in different failure mechanisms. The best quality of laminate was produced for the thinnest specimens (16-ply), and these had the highest strengths. The 48-ply laminates were of the poorest quality and had the lowest strength. All of the 48-ply specimens had large voids and resin pockets in the curved region that were visible to the naked eye. The 24-ply specimens had a quality in between that of the 16- and 48-ply laminates. The 24 -ply specimens with the $5.0-\mathrm{mm}$ radius all failed at the same ply interface because of a manufacturing defect at that interface.

The best indicator of strength for a given laminate was the local ply thicknesses. The highest strength configurations had the lowest ply thicknesses in the inner half of the thickness which also corresponds to the region of highest radial stress. In general, the quality of the laminate decreased from the inner radius to the outer radius. In Ref 4 , a similar result occurred when significantly

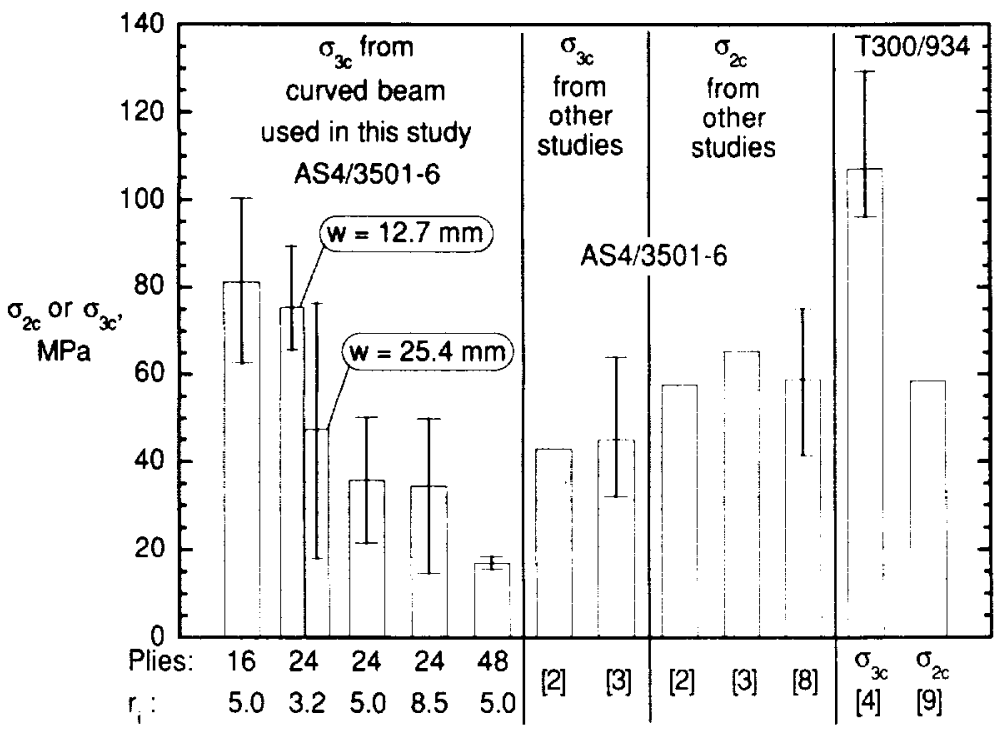

FIG. 15-Comparison of results with other studies. 
higher values of $\sigma_{3 c}$ were obtained for laminates where high compaction pressure was used in manufacturing curved specimens. Laminate quality cannot be assessed using C-scans since ultrasonic equipment cannot be used in highly curved regions. Manufacturing defects were most likely the initiation sites for much of the damage. The strength appeared to be extremely sensitive to flaws. The strength of the lower strength specimens was probably controlled by larger macroscopic defects such as voids. For specimens with higher strengths, the strength may have been a function of smaller microscopic flaws such as fiber/matrix debonds.

Strength results from several other studies were also plotted in Fig. 15 for comparison. The mean value of $\sigma_{3 \mathrm{c}}$ determined from flatwise tension tests [2] fell between the lower and higher strength groups. The mean value of $\sigma_{3 c}$ determined from L-shaped curved laminates [3] also fell within a similar range. However, the quality of the laminates used in these two studies was not known since no sectioning was done. Several values of $\sigma_{2 c}[2,3,8]$ are also shown in Fig. 15. These values of $\sigma_{2 c}$ were higher than the $\sigma_{3 \mathrm{c}}$ values measured in the other studies $[2,3]$ and in the low strength group of this study. However, these values of $\sigma_{2 \mathrm{c}}$ are still significantly less than the values of $\sigma_{3 \mathrm{c}}$ measured in the higher strength group in this study. This result is consistent with the results of Ref 4 . The average value of $\sigma_{3 c}$ determined from curved elliptical specimens made of T300/934 carbon/epoxy was almost twice the reported value of $\sigma_{2 c}$ [9] determined from transverse tension tests. The curved elliptical specimen was manufactured using very high compaction pressure which produced a very high quality specimen. T300/934 has very similar properties to the AS4/3501-6 used in the current study.

A Weibull statistical analysis [II] was conducted on the group of higher strength data sets. The high strength values of $\sigma_{3 \mathrm{c}}$ relative to the reported values of $\sigma_{2 \mathrm{c}}$ can be accounted for in terms of volumetric scaling. The transverse tension tests involve a uniform stress over a large volume of material while the interlaminar tension tests with curved beams have a nonuniform stress applied over a very small volume. In Ref 8 , Weibull scaling laws were used to scale data from transverse tension tests to specimens where only a small volume of material was under high stress. The results from Ref 8 indicate that Weibull scaling laws can accurately predict the difference in strength of transverse tension coupons and the $\sigma_{3 \mathrm{c}}$ values of the "good" quality curved beams tested in this study.

Strength data obtained from curved beam test specimens can be very relevant to the design process. Specimens with curved geometries present unique manufacturing problems that do not occur in flat panels. Consequently, failure modes and strengths obtained from curved beam specimens with manufacturing flaws will closely resemble those in the actual structure with similar flaws. However, if a specimen does not contain any significant flaws, a true material property may be measured. Because of the curved nature of the specimen, it is not possible to use conventional Cscan methods to determine specimen quality. Hence, the only means of determining specimen quality is by testing and, as in this work, obtaining sets of data that represent a range of part qualities. Similarly, in complex composite structures, quality cannot be determined using conventional $\mathrm{C}$-scans. Hence, all the data from the curved beam specimens, representing a range of specimen qualities, may be useful in predicting failure in a structure. Using the true material strength to design a structure may result in a very unconservative design.

In this study, interlaminar tensile strengths were highly dependent on the manufacturing quality of the specimens. This is a severe problem since the quality of highly curved parts cannot be routinely determined using conventional C-scans. Also, a high quality specimen was difficult to manufacture. However, several alternatives are available to improve the through-the-thickness strength of curved composite structures. The manufacturing process can be improved to consistently obtain a better quality part. A tougher matrix may be used to reduce the flaw sensitivity that a laminate with a brittle matrix has. A material system with through-the-thickness reinforcement such as textile preforms also may be used. If through-the-thickness reinforcement is used, the strength should be much greater than traditional laminates and less dependent on the manufacturing process. 


\section{Summary}

A curved beam, loaded so that the radius of curvature increases, produces an interlaminar tensile stress that is zero at the free surfaces and reaches a maximum at some location through the thickness. The tangential stress is tensile at the inside radius and compressive at the outside radius and small where the radial stress is a maximum. Therefore, if a unidirectional specimen is used with the fiber direction in the tangential stress direction, interlaminar tensile failure will occur. This paper described one configuration in which to test the curved beam as a method to determine interlaminar strength, $\sigma_{3 \mathrm{c}}$. Geometry effects of the specimen were studied; namely, the effects of loading arm length, inner radius, thickness, and width. The specimens generally did not fail along a single interface but developed many interlaminar and translaminar cracks. A wide range of strengths was measured which represented differences in laminate quality. For the lower strength specimens, failure may have occurred because of large macroscopic flaws such as voids or resin pockets which were observed in failed specimens. For the higher strength specimens, the failure was probably initiated by smaller microscopic flaws such as fiber/matrix debonds. The specimen geometries with the higher strengths tended to have lower ply thicknesses in the inner half of the thickness which corresponds to the region of highest stress. The $\sigma_{3 c}$ values determined from high quality specimens were significantly higher than the reported values of $\sigma_{2 \mathrm{c}}$ from transverse tension tests. This relative increase in strength can be accounted for by using volumetric scaling laws. From the data available, the loading arm length and width had little effect on $\sigma_{3 \mathrm{x}}$. The effects of thickness and inner radius could not be determined because of the large variation of laminate quality betwcen specimens of different curve geometries.

\section{APPENDIX A}

\section{Lekhnitskii Solution}

Lekhnitskii [6] developed a solution for the stresses in a curved beam with cylindrical anisotropy for two different loading cases: a curved beam under pure bending and a curved beam with an end force.

Case $\mathrm{I}$-Curved beam under pure bending (plane-stress)

$$
\begin{gathered}
\sigma_{r}^{\prime \prime}=-\frac{M}{r_{0}^{2} \omega g}\left[1-\frac{1-\rho^{\kappa+1}}{1-\rho^{2 \kappa}}\left(\frac{r}{r_{\theta}}\right)^{\kappa-1}-\frac{1-\rho^{\kappa-1}}{1-\rho^{2 \kappa}} \rho^{\kappa+1}\left(\frac{r_{b}}{r}\right)^{\kappa+1}\right] \\
\sigma_{\theta}^{m}=-\frac{M}{r_{r}^{2} w g}\left[1-\frac{1-\rho^{\kappa+1}}{1-\rho^{2 \kappa}} \kappa\left(\frac{r}{r_{0}}\right)^{\kappa-1}+\frac{1-\rho^{\kappa-1}}{1-\rho^{2 \kappa}} \kappa \rho^{\kappa+1}\left(\frac{r_{0}}{r}\right)^{\kappa+1}\right] \\
\tau_{r \theta}^{\prime \prime}=0
\end{gathered}
$$

where

$$
\begin{gathered}
g=\frac{1-\rho^{2}}{2}-\frac{\kappa}{\kappa+1} \frac{\left(1-\rho^{\kappa+1}\right)^{2}}{1-\rho^{2 \kappa}}+\frac{\kappa \rho^{2}}{\kappa-1} \frac{\left(1-\rho^{\kappa-1}\right)^{2}}{1-\rho^{2 \kappa}} \\
\kappa=\sqrt{\frac{E_{H}}{E_{r}}}
\end{gathered}
$$




$$
\rho=\frac{r_{i}}{r_{o}}
$$

Case II-Curved beam loaded by an end force (plane-stress)

$$
\begin{gathered}
\sigma_{r}^{f}=\frac{P}{r w g_{1}}\left[\left(\frac{r}{r_{o}}\right)^{\beta}+\rho^{\beta}\left(\frac{r_{o}}{r}\right)^{\beta}-1-\rho^{\beta}\right] \sin (\theta+\omega) \\
\sigma_{\theta}^{f}=\frac{P}{r w g_{1}}\left[(1+\beta)\left(\frac{r}{r_{o}}\right)^{\beta}+(1-\beta)\left(\frac{r_{o}}{r}\right)^{\beta} \rho^{\beta}-1-\rho^{\beta}\right] \sin (\theta+\omega) \\
\tau_{r t}^{f}=\frac{P}{r w g_{1}}\left[\left(\frac{r}{r_{0}}\right)^{\beta}+\rho^{\beta}\left(\frac{r_{o}}{r}\right)^{\beta}-1-\rho^{\beta}\right] \cos (\theta+\omega)
\end{gathered}
$$

where

$$
\begin{aligned}
& \beta=\sqrt{1+\frac{E_{\theta}}{E_{r}}\left(1-2 \nu_{r \theta}\right)+\frac{E_{\theta}}{G_{r \theta}}} \\
& g_{1}=\frac{2}{\beta}\left(1-\rho^{\beta}\right)+\left(1+\rho^{\beta}\right) \ln (\rho)
\end{aligned}
$$

The analysis was converted to plane strain by replacing $E_{r}, E_{\theta r}$ and $\nu_{r t}$ in Eqs 8, 13, and 14 by $\frac{E_{r}}{1-\nu_{v}, \nu_{r:}}, \frac{E_{\theta}}{1-\nu_{z \theta} \nu_{\theta z}}$, and $\frac{\nu_{r \theta}}{1-\nu_{s,} \nu_{r z}}\left(1+\frac{\nu_{z \theta} \nu_{r z}}{\nu_{r \theta}}\right)$, respectively.

The symbols are defined as:

of Subscript denoting modified stress equation for an end force

$E_{r}$ Modulus in the radial direction

$E_{\theta}$ Modulus in the tangential direction

$f$ Subscript denoting stress induced by an end force (Case II)

$G_{r \rightarrow}$ Shear modulus

$m$ Subscript denoting stress induced by a moment (Case I)

$M$ Applied moment

$P$ End force

$r . \theta$ Cylindrical coordinates of any point in the curved segment

$r_{i} \quad$ lnner radius of curved segment

$r_{1}$ Outer radius of curved segment

$w$ Width of the specimen

$\sigma_{r}, \sigma_{H}, \tau_{r+}$ Stress components in curved segment

$\nu$ Poisson's ratio

$\omega$ Angle of the load relative to the face of the loaded end of the curved segment Dimensions and variables are illustrated in Fig. 1.

\section{Correction to Lekhnitskii's End Force Solution}

The stress distribution applied to the end of the curved segment results in an end force resultant and an end moment resultant. Consequently, it was necessary to derive a correction to Lekhnitskii's end force solution to subtract out the additional moment. This correction is shown schematically in 
Fig. 3. This correction is not necessary when $\omega$ equals zero as was the case in Ref 3 . This moment per unit width $\left(M^{*}\right)$ applied to the end of the curved segment was calculated by integrating, along the face of the segment end, the product of the tangential stress component, $\sigma_{\theta}$, and the distance from the neutral axis.

$$
M^{*}=\int_{r_{t}}^{r_{\theta}} \sigma_{\theta \theta \theta=0)}\left(r-\frac{r_{1}+r_{n}}{2}\right) d r=\frac{P\left(r_{1}+r_{0}\right)}{2 w} \sin (\omega)
$$

The actual stresses in a curved beam caused by an end force resultant only were then calculated by subtracting the stresses caused by $M^{*}$ from Lekhnitskii's original end force solution. Lekhnitskii's solution for a beam under pure bending was used to calculate the stresses, caused by $M^{*}$.

$$
\begin{gathered}
\sigma_{r}^{c t}=\sigma_{r}^{f}-\sigma_{r M=M^{+1}}^{m} \\
\sigma_{H}^{c t}=\sigma_{H}^{f}-\sigma_{M M}^{m}=M^{+*} \\
\tau_{r H}^{\prime \prime}=\tau_{r H}^{f}
\end{gathered}
$$

\section{Final Stress Equations for the Interlaminar Tensile Strength Specimen}

The stresses in the interlaminar tensile strength specimen were calculated by superimposing the stresses from these two solutions (Eqs 19 through 21 ).

$$
\begin{aligned}
& \sigma_{r}=\sigma_{r}^{m}+\sigma_{r}^{\prime d} \\
& \sigma_{\theta}=\sigma_{H}^{m}+\sigma_{\theta}^{d t} \\
& \tau_{r \theta}=\tau_{r \theta}^{m}+\tau_{r \theta}^{c t}
\end{aligned}
$$

\section{APPENDIX B}

\section{Corrections to the Applied Moment}

The stress analysis was very sensitive to the changes in the length of the moment arm. An error in the moment arm length translates directly into the same percentage error in the stress calculation. Consequently, it was important to calculate the exact length of the moment arm at failure. Therefore, several corrections were considered for inclusion in the basic moment calculation. These corrections included the offset of the loading pin from the neutral axis and the shortening of the moment arm caused by the rotation and displacement of the end of the beam on loading.

The basic moment was simply calculated as the force. $P$. multiplied by the length, $L$, of the moment arm (Eq 22)

$$
M^{\text {tivici }}=P L \sin (45)
$$

Prior to loading, the moment arm length was reduced by the offset of the loading fixture from the neutral axis of the laminate (Fig. 1). This correction was calculated as 


$$
M^{\text {tingec }}=-P\left(\Delta+\frac{t}{2}\right) \sin (45)
$$

where $\Delta$ is the height of the hinge from the surface of the specimen, and $t$ is the specimen thickness. This was the most significant correction to the basic moment calculation. Omitting this correction resulted in an error up to $30 \%$ in some cases. This correction was more significant in the thicker specimens.

The next most significant correction was in accounting for the deflection of the end of the loading arm at failure. Simple beam theory was used to calculate the deflection caused by the transverse component of the load and caused by the moment created by the loading point offset from the neutral axis. A geometric nonlinear interaction exists between the tensile load and the transverse load. This interaction was accounted for using tabulated reaction coefficients $/ 10]$. The tensile load had a negligible effect on the deflection calculated from the moment and transverse load only. The deflection correction was the most significant for the 16-ply specimens where an average $4.1 \%$ crror would result if the deflection was not accounted for. However, the error was reduced for thicker specimens since the moment of inertia increases proportionally to the cube of the thickness. The average error for the 24-ply specimens was $2.5 \%$, and the error was less than $1 \%$ for the 48 -ply specimens. These errors were considered insignificant relative to the experimental error and were not taken into account in the final stress equation. The nonlinear effect of shortening from beam rotation was also calculated. This effect was most significant in the 16-ply specimens, but made less than a $0.2 \%$ difference in the overall moment calculation. Consequently, the effect of shortening was also neglected.

The final moment equation (24) that was used was the basic moment plus the correction for the hinge offset.

$$
M^{\text {(xtal })}=M^{\text {halici }}+M^{\text {thinge }}=P\left(L-\Delta-\frac{t}{2}\right) \sin (45)
$$

The effect of end displacement and rotation only becomes significant for very thin specimens with high loads and does not generally need to be included.

\section{Final Stress Equations for the Interlaminar Tension Strength Specimen}

Equation 24 was substituted into Eqs 19 through 21 to obtain the final equation for the stresses in the interlaminar tension strength specimen. The final equations ( 25 through 27 ) are shown.

$$
\begin{aligned}
& \sigma_{r}=\frac{P}{r w g_{1}}\left[\left(\frac{r}{r_{s}}\right)^{\beta}+\rho^{\beta}\left(\frac{r_{u}}{r}\right)^{\beta}-1-\rho^{\beta}\right] \sin (\theta+\omega) \\
& -\frac{P\left(L \cos (\omega)-\frac{1}{2}\left(r_{1}+r_{0}\right) \sin (\omega)-\left(\Delta+\frac{t}{2}\right) \sin (\omega)\right)}{r_{1}^{2} \omega g}\left[1-\frac{1-\rho^{\kappa+1}}{1-\rho^{2 \kappa}}\left(\frac{r}{r_{n}}\right)^{\kappa}\right. \\
& \left.-\frac{1-\rho^{\kappa-1}}{1-\rho^{2 \kappa}} \rho^{\kappa+1}\left(\frac{r_{r}}{r}\right)^{\kappa+1}\right] \\
& \sigma_{t}=\frac{P}{r w g_{1}}\left[(1+\beta)\left(\frac{r}{r_{0}}\right)^{\beta}+(1-\beta)\left(\frac{r_{t}}{r}\right)^{\beta} \rho^{\beta}-1-\rho^{\beta}\right] \sin (\theta+\omega)
\end{aligned}
$$




$$
\begin{gathered}
-\frac{P\left(L \cos (\omega)-\frac{1}{2}\left(r_{i}+r_{o}\right) \sin (\omega)-\left(\Delta+\frac{t}{2}\right) \sin (\omega)\right)}{r_{o}^{2} \omega g}\left[1-\frac{1-\rho^{\kappa+1}}{1-\rho^{2 \kappa}} \kappa\left(\frac{r}{r_{o}}\right)^{\kappa-1}\right. \\
\left.+\frac{1-\rho^{\kappa-1}}{1-\rho^{2 \kappa}} \kappa \rho^{\kappa+1}\left(\frac{r_{o}}{r}\right)^{\kappa+1}\right] \\
\tau_{r \theta}=\frac{P}{r \omega g_{1}}\left[\left(\frac{r}{r_{o}}\right)^{\beta}+\rho^{\beta}\left(\frac{r_{o}}{r}\right)^{\beta}-1-\rho^{\beta}\right] \cos (\theta+\omega)
\end{gathered}
$$

\section{References}

[l] Martin, R. H. and Sage, G. N., "Prediction of the Fatigue Strength of Bonded Joints Between MultiDirectional Laminates of CFRP." Composite Srructures, Vol. 6, 1986, pp. 141-163.

[2] Lagace, P. A. and Weems. D. B., "A Through-the-Thickness Strength Specimen for Composites," Test Methods for Design Allowables for Fibrous Composites: 2nd Volume, ASTM STP 1003, C. C. Chamis, Ed., American Society for Testing and Materials, Philadelphia, 1989, pp. 197-207.

[3] Martin, R. H. and Jackson, W. C., "Damage Prediction in Cross-Plied Curved Composite Laminates," in Composite Materials: Fatigue and Fracture, Fourth Volume, ASTM STP 1156, W. W. Stinchcomb and N. E. Ashbaugh. Eds., American Society for Testing and Materials. Philadelphia, 1993, pp. 105-126; also published as NASA TM 104089, July 1991.

[4] Hiel. C. C.. Sumich, M., and Chappell. D. P., "A Curved Beam Test Specimen for Determining the Interlaminar Strength of a Laminated Composite," Journal of Composite Materials, Vol. 25, July 1991. pp. 854-868.

[5] Kedward, K. T., Wilson, R. S., and McLean, S. K., "Flexure of Simply Curved Composite Shapes," Composites, Vol. 20, No. 6, November 1989 , pp. 527-536.

[6] Lekhnitskii, S. G.. Anisotropic Plates, Gordon and Breach Science Publishers, New York, 1968, pp. $95-101$.

[7] Kline, S. J. and McClintock, F. A., "Describing Uncertainties in Single-Sample Experiments," Mechanical Engineering, January 1953.

[8] O'Brien. T. K. and Salpekar, S. A., "Scale Effects on the Transverse Tensile Strength of Graphite Epoxy Composites," in Composite Materials: Testing and Design-Eleventh Volume, ASTM STP 1206, E. T. Camponeschi, Ed.. American Society for Testing and Materials, Philadelphia, 1993 (this publication); also published as NASA TM 1076.37. June 1991.

[9] Wu. H.-Y. T. and Springer. G. S.. "Impact Induced Stresses. Strains, and Delaminations in Composite Plates," Journal of Composite Materials, Vol. 22, 1988, pp. 533-560.

[10] Roark. R. J. and Young, W. C., Formulas for Stress and Strain. McGraw-Hill, Inc., New York, 1975, pp. $147-152$

[1/] Weibull, W., "A Statistical Theory of the Strength of Materials," Ing. Vetenskaps Akad. Handl., Roval Swedish Institule Engineering Research Proceedings, NR151, 1939.

[12] Rodini. B. T. and Eisenmann. J.. "An Analytical and Experimental Investigation of Edge Delamination in Composite Laminates," Fibrous Composites in Structural Design. Planum Publishers. New York, 1980, pp. $44 !-457$ 
. 
